Journal of Social Sciences 6 (3): 408-410, 2010

ISSN 1549-3652

(C) 2010 Science Publications

\title{
The Ways to Conserve and Develop Isan-Shadow Puppet Performances for Promoting Cultural Value and Worth
}

\author{
${ }^{1}$ Booncharoen Bamrungchoo, ${ }^{1}$ Boonsom Yodmalee and ${ }^{2}$ Khaentaphon Samdaengdej \\ The Research Institute of North Eastern Arts and Culture, \\ Mahasarakham University, Maha Sarakham, Thailand, 44001 \\ ${ }^{2}$ Faculty of Humanities and Social Sciences, Mahasarakham University, Thailand, 44150
}

\begin{abstract}
Problem statement: Nang Pra Mo Thai Isan (Isan-Shadow puppet performance) is a kind of cultural plays which has been performed for a long time. At present, it has declined from people's popularity so it should be conserved and developed in order to promote its folk-cultural value and worth. The purposes of this research were: (1) to investigate the diffusion, the background, the elements, the custom, the belief of Nang Pra Mo Thai (Isan-shadow performance) and the ways of life of Isan-shadow puppet performance groups, (2) to search for the ways to conserve and develop Nang Pro Mo Thai and (3) to search for the ways to promote folk-cultural value and worth of Nang Pra Mo Thai (Isan-shadow puppet performance). Approach: Research areas were Roi-Et, Yasothon, Ubon Ratchathani, Udon Thani, Khon Kaen and Maha Sarakham Province. Because Nang Pro Mo Thai groups (Isan-shadow puppet performance groups) have lived in these areas and they have moved to perform in all northeastern areas of Thailand. Research population was 51 Isan-shadow puppet performance groups and a sample consisted of the chiefs, the deputy chiefs, the assistant chiefs, the puppet operators, the dabbers and the musicians. Research data were collected by means of a survey, an interview, an observation and a focus group interview. Research results were presented by means of a descriptive analysis. Results: (1) The diffusion of Nang Pra Mo Thai performances have found frequently in the central and lower of northeast Thailand but have rarely found in the upper part. Knowledge of performing Nang Pra Mo Thai has been transmitted from generation to generation among family and relatives, (2) The ways to conserve and develop Nang Pra Mo Thai focused on the elements of a performance, the art of presentation, the system of light and sound, public relations and the time of a performance and (3) The ways to promote folk film for promoting Nang Pra Mo Thai, holding activities for promoting Nang Pra Mo Thai, holding Nang Pro Mo Thai-competitions, producing souvenirs, writing a history of Nang Pra Mo Thai, producing visual compact discs for promoting Nang Pra Mo Thai. Conclusion: According to these research results, the persons who are involved in conservation and development of Nong Pra Mo Thai (Isan-shadow puppet performance) can adapt them for the appropriate operation concerning their duties.
\end{abstract}

Key words: The ways to conserve and develop, Nang Pra Mo Thai (Isan-shadow puppet performance), cultural value, cultural worth

\section{INTRODUCTION}

The Northeast Part of Thailand, a region where is the centre of valuable culture, valuable customs and traditions; for example languages, food, handicrafts, historical sites, archaeological objects, plays and entertainments. These are indicators of Isan indigenous knowledge which have been handed down from generation to generation. A folk-entertainment which has played a role as a social entertainment together with Northeastern folksingers for a long time is Nang Pra Mo Thai (Wilailak, 2001).
The majority of Nang Pra Mo Thai groups (Isanshadow puppet performance groups) like to play a story of Ramayana but the minority create their new stories to play by themselves. At present, northeastern people rarely like to see Nang Pra Mo Thai because technology is growing so they like to see movie, watch televisions, see videotapes, listen to the radios and cassettes which are convenient and easy to get knowledge and entertainment rather than they get from Nang Pra Mo Thai. Thus nowadays there are a few of Nang Pra Mo Thai groups and they will disappear if nobody promotes or conserves them (Rattaporn, 1983).

Corresponding Author: Booncharoen Bamrungchoo, The Research Institute Northeastern of Art and Culture, Mahasarakham University, Maha Sarakham, Thailand, 44001 
Nang Pra Mo Thai (Isan-shadow puppet performance) is an important kind of folk-performance arts which has had its background for a long time. Although it has declined at present, it is a cultural identification of northeast people of Thailand which should be conserved continuously. Purposes and object: The purposes of this research were: (1) to investigate the diffusion, the background, the elements, the custom, the belief of Nang Pra Mo Thai and the ways of life of Nang Pra Mo Thai groups (Isan-shadow puppet performance groups), (2) to search for the ways to conserve and develop Nang Pra Mo Thai and (3) to search for the ways to promote folk-cultural value and worth of Nong Pra Mo Thai (Isan-shadow puppet performance).

\section{MATERIALS AND METHODS}

Population and sample: A population was all the people of 51 Nang Pra Mo Thai groups (Isan-shadow puppet performance groups). A sample consisted of the chiefs, the deputy chiefs, the assistant chiefs, the puppet operators, the dabbers and the musicians.

Instruments: Research data were collected by means of a survey, an interview, an observation and a focus group interview.

Data analysis: Research results were presented by means of a descriptive analysis.

\section{RESULTS}

The results of this research revealed the following:

- The diffusion of Nang Pro Mo Thai performances have found frequently in the central and lower of northeast Thailand but have rarely found in the upper part. At present, there are 51 Nang Pra Mo Thai groups (Isan-shadow puppet performance groups) in 13 provinces where are Udon Thani, Mukdahan, Nakhon Phanom, Kalasin, Khon Kaen, Maha Sarakham, Rot-Et, Nakhon Ratchasima, Buri Ram, Ubon Ratchathani, Amnat Charoen, Si Sa Ket and Yasothon. People sometimes call Nang Pra Mo Thai that "Nang Buk Pong Buk Kaew", "Nang Buk Tue" or "Nang Buk Si Kaew". For its background, nobody has written it before. The elements of Nang Pra Mo Thai performance of each group are different or similar, they depend on educational background and transmission technique of each trainer, including geographical feature, customs, traditions and environment of each area. Customary sequences of Nang Pra Mo Thai performance of each group are preparing, opening and performing a ceremony to show respect for trainers, giving a prelude and announcing a little, performing a story and ending a story. Each group of Nang Pra Mo Thai performs all activities like operating a puppet, dubbing, making a joke and integrating beliefs with respect for trainers. The ways of life of Nang Pra Mo Thai groups depend on the sufficiency of the four requisites of life like food, clothing, shelter and medicine. These are a social factor, an economic factor, a cultural factor and an environmental factor

- The ways to conserve and develop Nang Pra Mo Thai focused on the elements of a performance, the art of presentation, the system of light and sound, public relations and the time of a performance

- The ways to promote folk-cultural value and worth focused on producing a short film for promoting Nang Pra Mo Thai, holding activities for promoting Nang Pra Mo Thai, holding Nang Pra Mo Thai competitions, Producing souvenirs, writing a history of Nang Pra Mo Thai, producing visual compact discs for promoting Nang Pra Mo Thai

\section{DISCUSSION}

The diffusion of Nang Pra Mo Thai performances have found frequently in the central and lower of northeast Thailand but have rarely found in the upper part. At present, there are 51 Nang Pra Mo Thai groups in 13 provinces where are Udon Thani, Mukdahan, Nakhon Phanom, Kalasin, Khon Kaen, Maha Sarakham, Roi-Et, Nakhon Ratchasima, Buri Ram, Ubon Ratchathani, Amnat Charoen, Si Sa Ket and Yasothon. For its background, nobody has written it before so it has not been clear until now. This congruent with Rattaporn (1983), he writes that "Nang Pra Mo Thai performances are likely to dapt from shadow puppet performances of central part Thailand which are influenced by southern shadow puppet performances. The elements of Nang Pra Mo Thai of each group are different or similar, they depend on educational background and transmission technique of each trainer, including geographical feature, customs, traditions and environment of each area. Generally, customary sequences of Nang Pra Mo Thai performance are preparing, opening and performing a ceremony to show respect for trainers, giving a prelude and announcing a title, performing a story and ending a 
story. Each group of Nang Pra Mo Thai performs all activities, like operating a puppet, dubbing, making a joke and integrating beliefs with respect for trainers. The ways of life of Nang Pra Mo Thai groups depend on the sufficiency of the four requisites of life like food, clothing, shelter and medicine. These are a social factor, an economic factor, a cultural and an environmental factor. These factors affect the survival of Nang Pro Mo Thai groups.

The ways to conserve and develop Nang Pra Mo Thai focused on the elements of a performance, the art of presentation, the system of light and sound, public relations and the time of a performance. This is congruent with Dusit (1996), he writes in his thesis that "The people in shadow play groups who should be conserved and developed are chiefs, puppet operators, audience and puppet creators". The useful things for a shadow puppet performance which should be conserve and develop are theaters, screens, puppets, musical instruments and puppet stands. Moreover, people or persons involved should give a chance and a place for performing shadow puppet in order to develop its elements like customary sequences, titles, scripts and the art of presentation.

The ways to promote folk-cultural value and worth of Nang Pra Mo Thai focused on producing a short film, producing souvenirs, writing a history of Nang Pra Mo Thai, producing visual compact discs and holding Nang Pra Mo Thai competitions. This is congruent with Indira (1997), she writes in her thesis that "shadow puppet performances which are presented on television broadcasting, they rather transmit 4 issues to the public; for example social right conduct, AIDS awareness, a general knowledge of political situation and a knowledge of environmental conservation. Moreover, they play a role as transmitters of social right conduct, information and comments and these roles are congruent with Parichart (1994), she writes in her thesis that "The audience of shadow play performances receive information concerning public health from live performances, television and radio broadcasting".

\section{CONCLUSION}

These research results revealed the diffusion the background, the element, the custom, the belief of Nang Pra Mo Thai (Isan-shadow puppet performance), the ways of life of Nang Pro Mo Thai groups, the ways to conserve and develop Nang Pra Mo Thai and the ways to promote folk-cultural value and worth of it. The persons involved can apply these results as information for conserving and developing Nang Pra Mo Thai in other areas.

\section{ACKNOWLEDGEMENTE}

This research was supported by the Research Institute of Northeastern Art and Culture, Mahasarakham University. The researchers would like to express their sincere thanks to the Research Institute of Northeastern Art and Culture, Mahasarakham University, the groups of Nang Pra Mo Thai (Isan shadow play) in the 6 provinces of Roi-Et, Yasothon, Ubon Ratchathani, Udon Thani, Khon Kaen and Maha Sarakham and all persons who support this research.

\section{REFERENCES}

Dusit, R., 1996. The conservation and development of shadow plays according to the opinion of the chiefs of shadow play groups. Master of Arts Dissertation, Srinakharinwirot Songkhla University.

Indira, S., 1997. Knowledge transfer through shadow plays on television. Master of Arts (Communication Arts) Dissertation, Chulalongkorn University.

Parichart, Y., 1994. The reception of health information from the shadow play a traditional folk media. Master of Arts (Communication Arts) Dissertation, Chulalongkorn University.

Rattaporn, S., 1983. Nang Pra Mo Thai-The Isan Shadow Play. 1st Edn., Saksopha Karn Pim, Bangkok, pp: 65.

Wilailak, L., 2001. The changes of Nang Pra Mo Thai in Roi-Et province. Master of Arts Independent Study Dissertation, Mahasarakham University. 